Author affiliations and support information (if applicable) appear at the end of this article.

Published at jco.org on May 2, 2017.

Clinical trial information: NCT01203228.

Corresponding author: Nicolaus Kröger, MD, Department of Stem Cell Transplantation, University Medical Center Hamburg-Eppendorf, Martinistrasse52, D-20246 Hamburg, Germany; e-mail: nkroeger@uke. uni-hamburg.de

(c) 2017 by American Society of Clinical Oncology

0732-183X/17/3519w-2157w/\$20.00

\title{
Dose-Reduced Versus Standard Conditioning Followed by Allogeneic Stem-Cell Transplantation for Patients With Myelodysplastic Syndrome: A Prospective Randomized Phase III Study of the EBMT (RICMAC Trial)
}

Nicolaus Kröger, Simona Iacobelli, Georg-Nikolaus Franke, Uwe Platzbecker, Ruzena Uddin, Kai Hübel, Christof Scheid, Thomas Weber, Marie Robin, Matthias Stelljes, Boris Afanasyev, Dominik Heim, Giorgio Lambertenghi Deliliers, Francesco Onida, Peter Dreger, Massimo Pini, Stefano Guidi, Liisa Volin, Andreas Günther, Wolfgang Bethge, Xavier Poiré, Guido Kobbe, Marleen van Os, Ronald Brand, and Theo de Witte

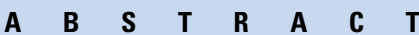

\section{Purpose}

To compare a reduced-intensity conditioning regimen $(\mathrm{RIC})$ with a myeloablative conditioning regimen (MAC) before allogeneic transplantation in patients with myelodysplastic syndrome (MDS) within a randomized trial.

\section{Patients and Methods}

Within the European Society of Blood and Marrow Transplantation, we conducted a prospective, multicenter, open-label, randomized phase III trial that compared a busulfan-based RIC with MAC in patients with MDS or secondary acute myeloid leukemia. A total of 129 patients were enrolled from 18 centers. Patients were randomly assigned in a 1:1 ratio and were stratified according to donor, age, and blast count.

\section{Results}

Engraftment was comparable between both groups. The $\mathrm{Cl}$ of acute graft-versus-host disease II to IV was $32.3 \%$ after RIC and 37.5\% after MAC $(P=.35)$. The $\mathrm{Cl}$ of chronic graft-versus-host disease was $61.6 \%$ after $\mathrm{RIC}$ and $64.7 \%$ after MAC $(P=.76)$. The $\mathrm{Cl}$ of nonrelapse mortality after 1 year was $17 \%(95 \% \mathrm{Cl}$, $8 \%$ to $26 \%)$ after $\mathrm{RIC}$ and $25 \%(95 \% \mathrm{Cl}, 15 \%$ to $36 \%)$ after $\mathrm{MAC}(P=.29)$. The $\mathrm{Cl}$ of relapse at 2 years was $17 \%(95 \% \mathrm{Cl}, 8 \%$ to $26 \%)$ after $\mathrm{RIC}$ and $15 \%(95 \% \mathrm{Cl}, 6 \%$ to $24 \%)$ after MAC $(P=.6)$, which resulted in a 2-year relapse-free survival and overall survival of $62 \%(95 \%$ $\mathrm{Cl}, 50 \%$ to $74 \%)$ and $76 \%(95 \% \mathrm{Cl}, 66 \%$ to $87 \%)$, respectively, after $\mathrm{RIC}$, and $58 \%(95 \% \mathrm{Cl}, 46 \%$ to $71 \%)$ and $63 \%(95 \% \mathrm{Cl}, 51 \%$ to $75 \%)$, respectively, after MAC ( $P=.58$ and $P=.08$, respectively).

\section{Conclusion}

This prospective, randomized trial of the European Society of Blood and Marrow Transplantation provides evidence that RIC resulted in at least a 2-year relapse-free survival and overall survival similar to MAC in patients with MDS or secondary acute myeloid leukemia.

\section{J Clin Oncol 35:2157-2164. (C) 2017 by American Society of Clinical Oncology}

\section{INTRODUCTION}

\section{ASSOCIATED CONTENT}

See accompanying Editorial on page 2106

(2) Appendix

DOI: https://doi.org/10.1200/JCO 2016.70.7349

(2) Data Supplement DOI: https://doi.org/10.1200/JCO 2016.70.7349

DOI: https://doi.org/10.1200/JCO.2016. 70.7349 compatible donors is still the treatment with the highest chance of cure, and the number of transplantations is steadily increasing, especially in older patients. ${ }^{3-6}$ This is primarily a result of increasing donor availability and the introduction of reduced-intensity conditioning regimens (RICs). ${ }^{7}$ Several retrospective studies from the European Group of Blood and Marrow Transplantation (EBMT) as well as larger centers have reported a higher risk of relapse but a lower rate of nonrelapse mortality (NRM) when comparing RIC with myeloablative conditioning regimens (MACs), which has resulted in comparable 
survival after both approaches. ${ }^{8-10}$ However, in all studies, the patient age was significantly higher in the RIC arm and smaller studies reported no difference in relapse rate if patients underwent transplantation in complete remission without active disease. ${ }^{11}$

To circumvent selection bias, we performed a prospective, multicenter, open-label phase III study comparing a busulfanbased standard myeloablative conditioning regimen with a busulfan-based RIC regimen in patients with MDS or secondary acute myeloid leukemia (sAML) and $<20 \%$ blasts (RICMAC Study).

\section{PATIENTS AND METHODS}

\section{Patient Characteristics}

In this prospective, multicenter, open-label randomized phase III study, patients were randomly assigned to receive a myeloablative conditioning regimen that consisted of busulfan $(16 \mathrm{mg} / \mathrm{kg}$ orally or $12.8 \mathrm{mg} /$ $\mathrm{kg}$ intravenously) and cyclophosphamide $(120 \mathrm{mg} / \mathrm{kg})$ or a an RIC regimen that consisted of busulfan ( $8 \mathrm{mg} / \mathrm{kg}$ orally or $6.4 \mathrm{mg} / \mathrm{kg}$ intravenously) and fludarabine $\left(150 \mathrm{mg} / \mathrm{m}^{2}\right)$ followed by allogeneic stem-cell transplantation from a related or unrelated donor. Detailed characteristics of patients are listed in Table 1.

Major inclusion criteria were cytologically proven MDS and sAML with $<20 \%$ of blasts at time of transplantation, a matched related or unrelated donor (one mismatch was allowed), age 18 to 60 years for unrelated donors and age 50 to 65 years for related donors, which was amended in $02 / 2006$ to age 18 to 65 years. Eighty-five percent of chemotherapies before transplantation were administered in advanced MDS (chronic myelomonocytic leukemia, refractory anemia with excess of blasts, and sAML) to reduce the number of blasts $(85 \%)$, whereas only $15 \%$ of chemotherapies were administered to less advanced MDS (refractory anemia, refractory anemia with ringsideroblasts, and refractory anemia with multilineage dysplasia). Other inclusion criteria were adequate hepatic, renal, pulmonary, and cardiac functions. Graft-versus-host disease (GVHD) prophylaxis consisted of cyclosporine and a short course of methotrexate $\left(10 \mathrm{mg} / \mathrm{m}^{2}\right.$ on days $+1,+3,+6$, and +11$)$ for both arms. In the case of unrelated donor antilymphocyte globulin (Fresenius, Graefelfing, Germany) at a cumulative does of 30 to $60 \mathrm{mg} / \mathrm{kg}$ or antithymocyte globulin (Thymoglobulin; Sanofi, Paris, France) at a cumulative dose of 6 to $10 \mathrm{mg} / \mathrm{kg}$ could be administered divided on days $-3,-2$, and -1 or alemtuzumab $100 \mathrm{mg}$ divided on days -8 to -4 according to center policy; however, alemtuzumab was not used in a single patient.

\section{Supportive Care}

Cyclosporine A dose was adjusted to a whole-blood level between 200 and $300 \mu \mathrm{g} / \mathrm{L}$ and should be tapered from day +120 to be discontinued at day +180 . All patients received fluconazole or other antifungal prophylaxis according to local policy. Antibacterial prophylaxis consisted of ofloxacin or ciprofloxacin and antiviral prophylaxis of acyclovir. Cytomegalovirus (CMV) reactivation was treated pre-emptively with ganciclovir or foscarnet. Further anti-infective prophylaxis consisted of twice weekly cotrimoxazole or monthly inhalation with pentamidine. Blood products were administered according to local policy. Epstein-Barr virus reactivation was defined as positive DNA assay on whole blood or plasma, according to center policy. CMV reactivation was defined as positive CMV pp65 antigenemia and/or DNA assay.

The primary end point of the study was NRM after 1 year. Secondary end points were comparison of engraftment, toxicity, acute and chronic GVHD, infectious complications, and event-free survival and overall survival at 2 years.

Acute GVHD was scored according to Glucksberg, ${ }^{12}$ whereas chronic GVHD was scored according to Shulman criteria (limited and extensive). ${ }^{13}$

The RICMAC Study was conducted in accordance with good clinical practice guidelines and the provisions of the Declaration of Helsinki. Protocol

\begin{tabular}{|c|c|c|c|}
\hline Characteristic & $\begin{array}{l}\text { Standard } \\
\text { Conditioning, } \\
\text { No. }(n=64)\end{array}$ & $\begin{array}{l}\text { Reduced-Intensity } \\
\text { Conditioning, } \\
\text { No. }(n=65)\end{array}$ & ty \\
\hline Age, years & & & .874 \\
\hline Median (range) & $50(19-64)$ & $51(22-63)$ & \\
\hline$\leq 45$ & 15 & 15 & \\
\hline $46-50$ & 17 & 16 & \\
\hline $51-55$ & 10 & 17 & \\
\hline $56-60$ & 19 & 13 & \\
\hline $61-65$ & 3 & 4 & \\
\hline $\begin{array}{l}\text { Diagnosis according } \\
\text { to WHO }\end{array}$ & & & $.569 *$ \\
\hline $5 q$ & 0 & 2 & \\
\hline CMML & 3 & 3 & \\
\hline MDS unclassifiable & 2 & 3 & \\
\hline RA & 4 & 3 & \\
\hline RARS & 5 & 3 & \\
\hline RAEB-1 & 12 & 19 & \\
\hline RAEB-2 & 15 & 17 & \\
\hline $\mathrm{RCMD}$ & 12 & 8 & \\
\hline RCMD-RS & 1 & 3 & \\
\hline sAML & 8 & 4 & \\
\hline Missing & 2 & & \\
\hline $\begin{array}{l}\text { Prior induction } \\
\text { chemotherapy }\end{array}$ & & & .253 \\
\hline No & 33 & 40 & \\
\hline Yes & 31 & 25 & \\
\hline Donor & & & .962 \\
\hline Matched related & 17 & 16 & \\
\hline Matched unrelated & 36 & 38 & \\
\hline $\begin{array}{l}\text { Mismatch unrelated/ } \\
\text { related }\end{array}$ & 11 & 11 & \\
\hline ATG as GVHD prophylaxis & & & .791 \\
\hline No & 31 & 33 & \\
\hline Yes & 33 & 32 & \\
\hline Blasts at transplantation & & & .034 \\
\hline Median (range) & $4 \%(0-18)$ & $5 \%(0-18)$ & \\
\hline$>5 \%$ & 18 & 30 & \\
\hline$\leq 5 \%$ & 46 & 35 & \\
\hline Recipient sex & & & .916 \\
\hline Male & 38 & 8 & \\
\hline Female & 26 & 27 & \\
\hline Donor sex & & & .846 \\
\hline Male & 40 & 43 & \\
\hline Female & 22 & 22 & \\
\hline Missing & 2 & & \\
\hline Gender mismatch & & & .285 \\
\hline Male/female & 9 & 14 & \\
\hline Others & 53 & 51 & \\
\hline Missing & 2 & & \\
\hline $\begin{array}{l}\text { Recipient/donor CMV } \\
\text { constellation }\end{array}$ & & & .250 \\
\hline Negative/negative & 28 & 21 & \\
\hline Positive/negative & 12 & 9 & \\
\hline Negative/positive & 10 & 9 & \\
\hline Positive/positive & 14 & 24 & \\
\hline Missing & & 2 & \\
\hline IPSS at diagnosis & & & $.737^{*}$ \\
\hline Low risk & 2 & & \\
\hline Intermediate I & 28 & 25 & \\
\hline Intermediate II & 18 & 24 & \\
\hline High risk & 9 & 7 & \\
\hline Missing & 7 & 7 & \\
\hline Cytogenetic risk & & & .650 \\
\hline Low & 24 & 28 & \\
\hline Intermediate & 17 & 13 & \\
\hline High & 17 & 18 & \\
\hline Missing & 6 & 6 & \\
\hline \multicolumn{4}{|c|}{ (continued on following page) } \\
\hline
\end{tabular}




\begin{tabular}{|c|c|c|c|}
\hline Characteristic & $\begin{array}{l}\text { Standard } \\
\text { Conditioning, } \\
\text { No. }(n=64)\end{array}$ & $\begin{array}{l}\text { Reduced-Intensity } \\
\text { Conditioning, } \\
\text { No. }(n=65)\end{array}$ & y \\
\hline $\begin{array}{l}\text { ECOG performance } \\
\text { status at diagnosis }\end{array}$ & & & $.692^{*}$ \\
\hline 0 & 18 & 21 & \\
\hline 1 & 32 & 29 & \\
\hline 2 & 3 & 3 & \\
\hline 3 & 0 & 2 & \\
\hline Missing & 11 & 10 & \\
\hline Busulfan & & & .053 \\
\hline Intravenously & 47 & 38 & \\
\hline Orally & 16 & 27 & \\
\hline Missing & 1 & 0 & \\
\hline Stem cell source & & & .311 \\
\hline Bone marrow & 3 & 6 & \\
\hline PBSC & 61 & 59 & \\
\hline
\end{tabular}

Abbreviations: ATG, antilymphocyte globulin; CMML, chronic myelomonocytic leukemia; CMV, cytomegalovirus; ECOG, Eastern Cooperative Oncology Group; GVHD, graft-versus-host disease; IPSS, International Prognostic Scoring System: MDS, myelodysplastic syndrome; PBSC, peripheral blood stem cell; RA refractory anemia; RAEB, refractory anemia with excess of blasts; RARS, refractory anemia with ringsideroblasts; RCMD, refractory anemia with multilineage dysplasia; SAML, secondary acute myeloid leukemia.

*Diagnosis: RAEB-1/RAEB-2/sAML/CMML $v$ other; IPSS at diagnosis: lowintermedia I $v$ intermediate II $v$ high; ECOG performance status, 0 v 1-3.

approval was obtained from an independent ethics committee at each study site. All patients provided written informed consent. EBMT sponsored the study.

\section{Statistical Methods}

The study planned to enroll 160 patients to detect a difference in 1 -year treatment-related mortality of $40 \%$ after MAC versus $20 \%$ after RIC with a power of $90 \%$ and a significance level of $5 \%$ in a two-sided test using a proportional hazards model. As a result of a slow accrual rate, inclusion stopped when 129 patients were enrolled. At that moment, a blinded power calculation on the basis of the same hypotheses on expected NRM rates and in various likely scenarios for relapse rate returned power superior to $80 \%$ with a sample size of 120 patients. It was thus considered appropriate to stop the accrual and proceed with the final analysis. This showed, however, actual NRM rates lower than expected, in particular, in the MAC arm; thus, the study was underpowered $(<35 \%)$ to detect a true difference in NRM that was equal to the observed difference.

Therapy-related mortality-NRM - and relapse were analyzed in a competing risks framework by using the cumulative incidence estimator and the Gray test for univariable analysis as well as Cox proportional hazards regression for analysis of cause-specific hazards. Overall survival and relapse-free survival were estimated by using the Kaplan-Meier method and compared with the Log-Rank test in univariable analysis, and by Cox proportional hazards regression in multivariable analysis. Stratification factors (donor type, blasts, age) as well as patient and donor gender or gender mismatch, CMV status combination, diagnosis subgroup (sAML $v$ other), cytogenetics, International Prognostic Scoring System score, performance status, prior chemotherapy, and use of busulfan were considered for inclusion in Cox models with the random assignment arm. Selection was done on the basis of significance, taking into account prior clinical knowledge, the presence of missing values, and aspects related to model validation. Cases with missing values for one variable were excluded, but we confirmed the robustness of the results when including the missing variable as a further level. The proportional hazards assumption in Cox models was assessed by analysis of scaled Schoenfeld residuals, and no relevant departure was detected. The study was not specifically powered to investigate interactions and perform subgroup analyses. Following protocol, subgroup analyses were performed when the corresponding interaction term with the random assignment arm was found to be significant at the $10 \%$ level in the Cox proportional hazards regression model.
Acute and chronic GVHD were assessed by using the crude cumulative incidence estimator and the Gray test considering relapse and death as competing risks. Incidences of infections were estimated in terms of rates (for 100 person-years), and a Poisson-based exact method was used for testing rate ratios. Occurrence of serious adverse events as well as categorical characteristics were compared by $\chi^{2}$ or Fisher's exact test, and the Mann-Whitney test was used for continuous variables.

All end points were analyzed including all randomly assigned patients grouped according to random assignment arm, except secondary safety end points, which were analyzed in the subpopulation of patients who were treated according to protocol $(\mathrm{n}=125$; Fig 1$)$. Following study protocol that required a follow-up of 2 years, all end points were artificially censored at 24 months. Curves are not displayed beyond this time because only a minority of patients had longer follow-up.

Analyses were performed by using SPSS for Windows version 23 (SPSS, Chicago, IL) and R package version 3.1.0 (The R Foundation, Vienna, Austria; libraries survival, prodlim, cmprsk, and exactci).

\section{Random Assignment Procedure}

Patients were randomly assigned in a 1:1 ratio and stratified according to donor (related $v$ unrelated) blasts $(<5 \%$ or $>5 \%)$ and age $(<45$ years or $>45$ years). Patient flow is shown in Fig 2.

\section{RESULTS}

\section{Patients and Treatment}

Between May 2004 and December 2012, a total of 129 patients were enrolled in 18 centers and seven countries. Baseline characteristics of the remaining 129 patients were well balanced (Table 1).

\section{Graft Failure and Engraftment}

Four and three graft failures occurred after standard and RIC regimens, respectively $(P=.72)$. Median time for leukocyte engraftment (absolute neutrophil count $\geq 0.5 \times 10^{9} / \mathrm{L}$ ) was 15 days in each arm, and for platelet $\left(\geq 50 \times 10^{9} / \mathrm{L}\right.$ ) engraftment, 15 days (range, 4 to 158 days) in the RIC arm versus 16 days (range, 10 to 185 days $)$ in the standard $\operatorname{arm}(P=.33$; Table 2$)$.

\section{Acute and Chronic GVHD}

Cumulative incidence of acute GVHD grade II to IV and grade III and IV was $32.3 \%$ and $15 \%$ in the RIC arm, respectively, and $37.5 \%$ and $14 \%$ in the standard arm, respectively $(P=.35$; Table 2$)$. The CI of chronic GVHD at 24 months was $61.6 \%$ (95\% CI, 48.9\% to $74.3 \%$ ) in the RIC arm and $64.7 \%$ (95\% CI, $51.3 \%$ to $78.1 \%$ ) in the standard arm $(P=.76)$.

\section{Toxicity and NRM}

Infectious complications were more frequently observed in the standard arm (rate in 100 patient-years at day 100, $6.9 v 4.3$; $P=.002)$. There was no difference in CMV reactivation, EBV reactivation, or other viral or fungal infection (Table 2). Venoocclusive disease was reported in four patients in the MAC arm and no patients in the RIC arm, but no patient died of veno-occlusive disease. NRMs at 1 year was $16.9 \%$ (95\% CI, $7.8 \%$ to $26.0 \%)$ in the RIC arm and $25.3 \%$ (95\% CI, $14.6 \%$ to $36 \%$ ) in the standard arm $(P=.29$; Table 2 and Fig $2 \mathrm{~A})$. 


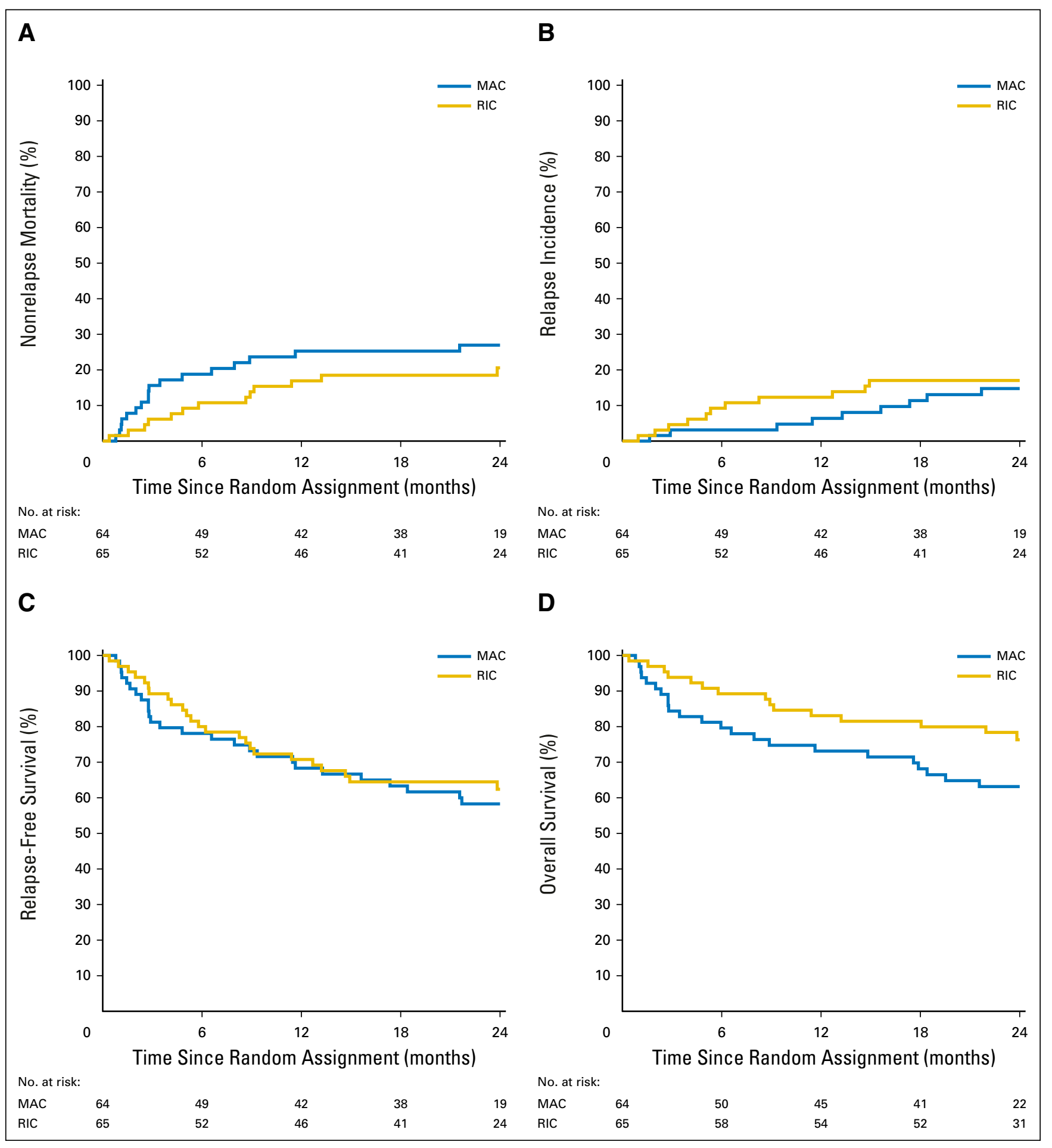

Fig 1. (A-D) Nonrelapse mortality (A), relapse incidence (B), relapse-free survival (C), and overall survival (D) according to intensity of conditioning regimen. MAC myeloablative conditioning; $\mathrm{RIC}$, reduced-intensity conditioning.

Organ toxicity according to Bearman's score did not differ, apart from stomatitis, which was significantly lower in the RIC arm ( $P=.05$; Appendix Tables A1 and A2, online only)

\section{Relapse}

The CI of relapse at 2 years was $17.0 \%(95 \%$ CI, $7.9 \%$ to $26.2 \%)$ in the RIC arm and $14.8 \%(95 \%$ CI, $5.8 \%$ to $23.7 \%)$ in the standard arm $(P=.64$; Table 2 and Fig $2 \mathrm{~B})$.

\section{Survival}

The 2-year relapse-free survival was $62.4 \%$ (95\% CI, $50.4 \%$ to $74.4 \%$ ) in the RIC arm and $58.3 \%$ (95\% CI, $46.0 \%$ to $70.6 \%$ ) in the standard arm $(P=.58)$, and 2-year overall survival was $76.3 \%(95 \%$ CI, $65.8 \%$ to $86.9 \%)$ after RIC versus $63.2 \%$ (95\% CI, $51.1 \%$ to $75.2 \%)$ after standard conditioning, respectively $(P=.08$; Table 2 and Figs $2 \mathrm{C}$ and 2D). 


\begin{tabular}{|c|c|c|c|}
\hline & Standard Conditioning & $\begin{array}{l}\text { Reduced-Intensity } \\
\text { Conditioning }\end{array}$ & $P$ \\
\hline Graft failure & 4 & 3 & .72 \\
\hline $\begin{array}{l}\text { Median time for leukocytes }>1.0 \times 10^{9} / \mathrm{L} \\
\text { (range), days }\end{array}$ & $15(9-32)$ & $15(4-25)$ & .81 \\
\hline $\begin{array}{l}\text { Median time for platelets }>50 \times 10^{9} / \mathrm{L} \\
\text { (range), days }\end{array}$ & $16(10-185)$ & $15(4-158)$ & .33 \\
\hline Acute GVHD, No. (\%) & & & .35 \\
\hline Grade 1 & $8(13)$ & $13(20)$ & \\
\hline Grade 2 & $15(23)$ & $11(17)$ & \\
\hline Grade 3 & $6(9)$ & $9(14)$ & \\
\hline Grade 4 & $3(5)$ & $1(1)$ & \\
\hline Chronic GVHD, No. (\%) & & & .76 \\
\hline Limited & $11(22)$ & $13(23)$ & \\
\hline Extensive & $21(41)$ & $25(44)$ & \\
\hline Overall No. of infections & 48 & 44 & \\
\hline Rate (per 100 person-years) day $1-100$ & $6.9(5.7-8.4)$ & $4.3(3.4-5.4)$ & .002 \\
\hline Rate (per 100 person-years) total follow-up & $2.0(1.7-2.3)$ & $1.4(1.2-1.6)$ & .002 \\
\hline Overall No. of bacterial infections & 31 & 22 & \\
\hline Rate (per 100 person-years) day $1-100$ & $2.3(1.6-3.2)$ & $1.3(0.8-1.9)$ & .029 \\
\hline Rate (per 100 person-years) total follow-up & $0.6(0.4-0.8)$ & $0.4(0.3-0.5)$ & .133 \\
\hline Overall No. of $\mathrm{CMV}$ reactivation, No. & 12 & 18 & .17 \\
\hline Overall No. of EBV reactivation, No. & 8 & 11 & .49 \\
\hline Overall No. of viral infections, No. & 21 & 14 & .24 \\
\hline No. of bacterial infections until day 100, No. & 28 & 17 & .03 \\
\hline Number of fungal infections until day 100 , No. & 11 & 8 & .53 \\
\hline Nonrelapse mortality at 1 year, \% $(95 \% \mathrm{Cl})$ & $25.3(14.6$ to 36.0$)$ & 16.9 (7.8 to 26.0$)$ & .29 \\
\hline Relapse incidence at 2 years, $\%(95 \% \mathrm{Cl})$ & $14.8(5.8$ to 23.7$)$ & 17.0 (7.9 to 26.2$)$ & .64 \\
\hline Relapse-free survival at 2 years, $\%(95 \% \mathrm{Cl})$ & $58.3(46.0$ to 70.6$)$ & $62.4(50.4$ to 74.4$)$ & .58 \\
\hline Overall survival at 2 years, $\%(95 \% \mathrm{Cl})$ & $63.2(51.1$ to 75.2$)$ & 76.3 (65.8 to 86.9$)$ & .08 \\
\hline Cause of death & & & .18 \\
\hline Disease related & 5 & 2 & \\
\hline Transplant related & 18 & 11 & \\
\hline Other & 0 & 2 & \\
\hline
\end{tabular}

\section{Multivariable and Subgroup Analyses}

In a multivariable analysis (MVA), NRM was influenced by performance status (Eastern Cooperative Oncology Group performance status $>0$ : hazard ratio [HR], 3.68; $95 \% \mathrm{CI}, 1.26$ to 10.76; $P=.02$ ) and cytogenetic risk (HR low $v$ intermediate, 5.63; 95\% CI, 1.28 to 24.82; $P=.02$; HR high $v$ intermediate, 4.28 ; $95 \%$ CI, 0.91 to $20.19 ; P=.07$ ), whereas for RIC, only a trend for lower NRM was noted (HR, 0.63 ; 95\% CI, 0.28 to $1.40 ; P=.26$; Table 3 ). In the model of NRM, an interaction was found between the random assignment arm and cytogenetics $(P=.08)$, which led to a subgroup analysis stratified by cytogenetics risk group. In the low-risk group, the RIC arm resulted in lower NRM (HR, 0.30; $95 \% \mathrm{CI}, 0.10$ to $0.89 ; P=.03)$. In the intermediate- and high-risk cytogenetic groups, RIC resulted in a higher NRM (HR, 1.17; 95\% CI, 0.07 to $18.83 ; P=.9$; and HR, $2.14 ; 95 \% \mathrm{CI}$, 0.51 to $9.00 ; P=.3$, respectively). A conclusive answer for this observation cannot be given, but a possible explanation would be that low-risk patients are protected from relapse and are thus more at risk for death without relapse. No other interaction was found.

In an MVA for relapse, advanced disease resulted in a higher risk (HR, 13.26; 95\% CI, 1.77 to 99.14; $P=.01$ ), whereas RIC had an HR of only 1.05 ( $95 \% \mathrm{CI}, 0.44$ to $2.54 ; P=.9$ ). Advanced disease was also a significant risk factor for lower relapse-free survival (HR, 2.77; 95\% CI, 1.30 to 5.91; $P=.008$ ), whereas RIC was not (HR, 1.05 ; $95 \% \mathrm{CI}, 0.44$ to $2.54 ; P=.9$ ). In an MVA for overall survival, worse survival was noted for low versus intermediate cytogenetic risk (HR, 6.06; 95\% CI, 1.69 to $21.80 ; P=.005$ ), for high versus intermediate cytogenetic risk (HR, 4.51; 95\% CI, 1.28 to 15.86 ; $P=.02$ ), and for advanced disease (HR, 2.26; $95 \% \mathrm{CI}, 0.95$ to 5.39 ; $P=.06$ ), whereas RIC resulted in improved overall survival (HR, $0.41 ; 95 \% \mathrm{CI}, 0.19$ to $0.87 ; P=.02$ ).

\section{DISCUSSION}

In this prospective, multicenter, multinational phase III study of the EBMT RIC regimen, administration before allogeneic stem-cell transplantation in patients with MDS was at least equivalent to the results after treatment with a standard myeloablative conditioning regimen. The CI of relapse at 2 years was nearly identical independent of conditioning regimen intensity, whereas NRM tended to be higher after myeloablative conditioning, although not significantly. The only risk factor for relapse in a multivariable analysis was advanced disease status, which was defined as CMML, RAEB, or SAML.

The role of conditioning regimen intensity before allogeneic stem-cell transplantation for MDS has not been studied prospectively and recommendations are based on retrospective singlecenter or registry studies. ${ }^{8,10}$ Despite this lack of evidence, the European Leukemia Net recommended a standard myeloablative 


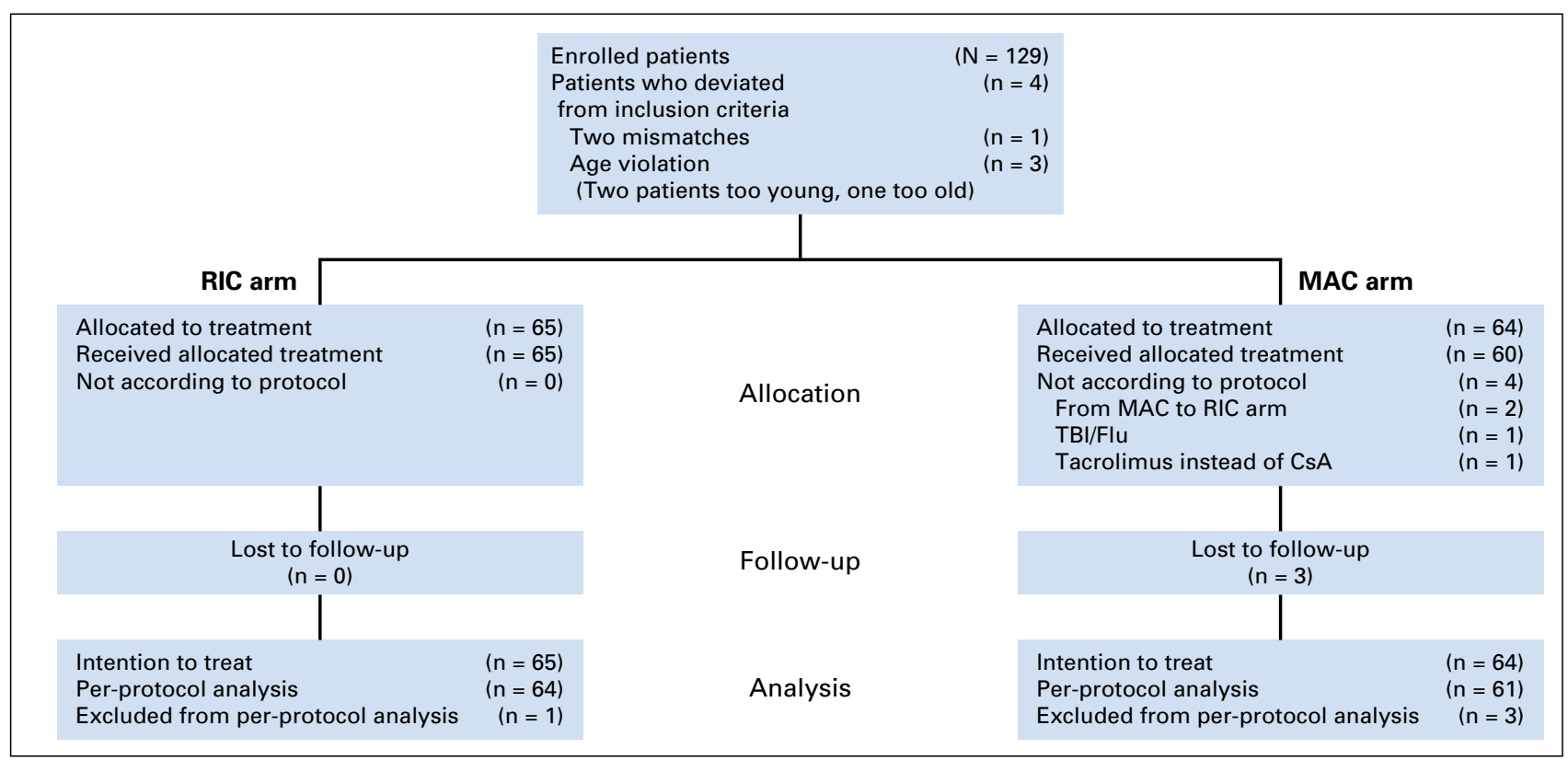

Fig 2. Flow diagram of the study. Four patients deviated from the inclusion criteria: one patient had two mismatches in HLA between patient and donor, one patient was

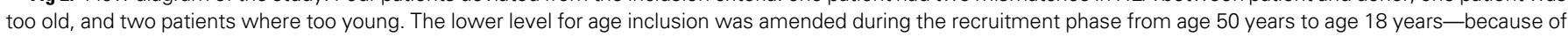

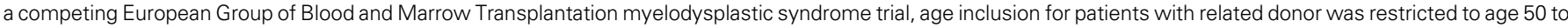

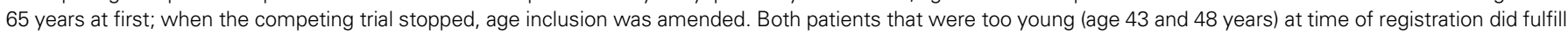

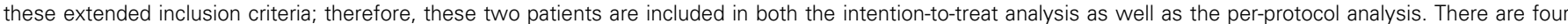

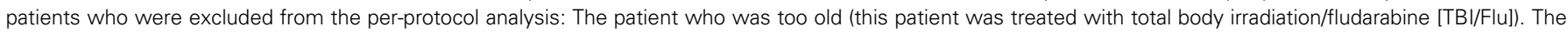

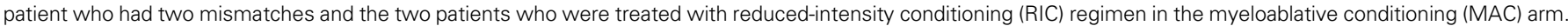
The patient who was treated with tacrolimus instead of cyclosporine A (CsA) was included in both the intention-to-treat analysis and the per protocol analysis.

conditioning regimen for all patients without comorbidities. Those patients with comorbidities should receive RIC, preferably within a clinical trial. ${ }^{1}$ The rationale for using RIC before allogeneic stemcell transplantation is to shift from high-dose chemotherapy that is aimed at maximizing cytotoxic leukemia killing to a more immune-mediated effect by harvesting the graft-versus-tumor effect to eradicate the disease. Retrospective registry studies have suggested a low risk of NRM but a higher risk of relapse after RIC; however, patients who received RIC were older than those who received standard myeloablative conditioning. ${ }^{4,8}$ To avoid selection bias in the study, all patients should have been eligible for standard myeloablative conditioning at the time of study inclusion; however, enrollment in the study was rather slow, which may be a result of the strict inclusion criteria for age and also because of patients declining to be randomly assigned and physician concern, because several retrospective studies suggested a higher risk of relapse after RIC; therefore, selection bias cannot be excluded. RIC is thought to result in lower toxicity and lower mortality. Regarding toxicity, we noted only significantly less stomatitis, which resulted only in a trend for a lower NRM. Because mismatch unrelated donors were included in this study, the NRM of MAC was surprisingly low and the observed 25\% NRM was much lower than the hypothesized $40 \%$ in the study protocol. A higher number of infections-mainly of bacterial origin-was observed after MAC conditioning. Another unexpected result was the higher NRM for the low-risk cytogenetic group compared with intermediate cytogenetic risk. In a nonpowered subanalysis for NRM, RIC in the low-risk group resulted in lower NRM. In the intermediate- and high-risk cytogenetic groups, RIC resulted in a higher but nonsignificant
NRM. Our analysis is not conclusive regarding the role of RIC in the high-risk group. Advanced disease is a significant factor for relapse-free survival and overall survival, but our study protocol did not allow subgroup analyses if interaction was $P>.1$.

In a multivariate analysis for overall survival, RIC resulted in a significant survival benefit at 2 years. Improved survival after RIC might be a result of lower mortality after relapse. Whereas after MAC six of nine patients who experienced relapse died, in the RIC arm, only two of 11 patients who experienced relapse died.

Whereas retrospective studies suggest a higher risk of relapse but a lower NRM after RIC, there are few available prospective studies that show similar survival rates. These studies, however, included mainly or only patients with AML who may differ in outcome from patients with MDS. In a German multicenter study, patients with AML in 1. Complete remission reduced-intensity total body irradiation-based conditioning regimen resulted in no significant difference in NRM, relapse incidence, and disease-free survival and overall survival compared with a standard myeloablative conditioning regimen. ${ }^{14}$

In older patients with AML who were in remission, a busulfan-based RIC regimen resulted in a lower NRM but similar overall survival. ${ }^{15}$ These trials, however, included only patients with AML. A recent multicenter US trial that compared RIC versus myeloablative conditioning and that included patients with AML and MDS was closed prematurely because of inferior outcome after RIC (BMT-CTN 0901 trial); however, the superior effect for survival of myeloablative conditioning was seen observed in patients with AML but not in those with MDS. ${ }^{16}$ Whereas in recent years the 


\begin{tabular}{|c|c|c|}
\hline Parameter & $\mathrm{HR}(95 \% \mathrm{Cl})$ & $P$ \\
\hline \multicolumn{3}{|l|}{ Nonrelapse mortality } \\
\hline $\mathrm{RIC}$ & $0.63(0.28$ to 1.40$)$ & .26 \\
\hline Cytogenetics & & .02 \\
\hline Low risk & 5.63 (1.28 to 24.82$)$ & .02 \\
\hline High risk & 4.28 (0.91 to 20.19$)$ & .07 \\
\hline$E C O G>0$ & 3.68 (1.26 to 10.76$)$ & .02 \\
\hline \multicolumn{3}{|l|}{ Relapse } \\
\hline RIC & 1.05 (0.44 to 2.54$)$ & .91 \\
\hline Advanced disease & $13.26(1.77$ to 99.14$)$ & .01 \\
\hline \multicolumn{3}{|l|}{ Relapse-free survival } \\
\hline $\mathrm{RIC}$ & $0.76(0.42$ to 1.38$)$ & .36 \\
\hline Advanced disease & $2.77(1.30$ to 5.91$)$ & .008 \\
\hline \multicolumn{3}{|l|}{ Overall survival } \\
\hline RIC & 0.41 (0.19 to 0.87 ) & .02 \\
\hline Cytogenetics & & $<.001$ \\
\hline Low risk & 6.06 (1.69 to 21.80$)$ & .005 \\
\hline High risk & 4.51 (1.28 to 15.86$)$ & .02 \\
\hline$E C O G>0$ & 2.32 (0.99 to 5.43$)$ & .05 \\
\hline Advanced disease & 2.26 (0.95 to 5.39$)$ & .06 \\
\hline \multicolumn{3}{|c|}{ 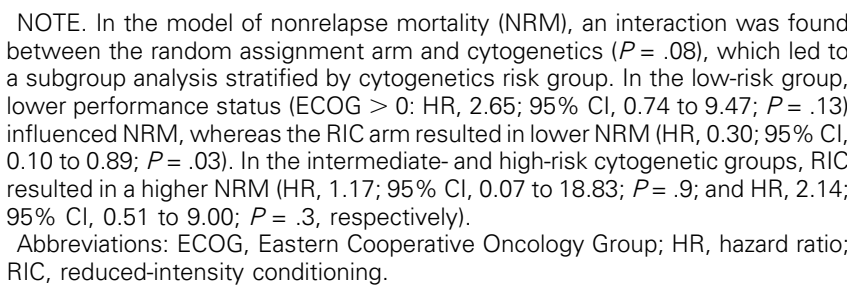 } \\
\hline
\end{tabular}

number of allogeneic stem-cell transplantation for older patients with MDS have increased, ${ }^{3}$ in our study, the majority of patients were age $<60$ years, because the upper age limit in the study was age 60 years for unrelated donor and age 65 years for related donor.

In summary, our study shows that RIC and MAC followed by allogeneic stem-cell transplantation resulted in at least an equivalent survival trend for a better 2-year overall survival, especially in the cytogenetic low-risk group and can be offered as an alternative to a myeloablative regimen.

\section{AUTHORS' DISCLOSURES OF POTENTIAL CONFLICTS OF INTEREST}

Disclosures provided by the authors are available with this article at jco.org.

\section{AUTHOR CONTRIBUTIONS}

Conception and design: Nicolaus Kröger, Theo de Witte

Provision of study materials or patients: Georg-Nikolaus Franke, Uwe Platzbecker, Kai Hübel, Christof Scheid, Thomas Weber, Marie Robin, Matthias Stelljes, Boris Afanasyev, Dominik Heim, Giorgio Lambertenghi Deliliers, Francesco Onida, Peter Dreger, Massimo Pini, Stefano Guidi, Liisa Volin, Andreas Güenther, Wolfgang Bethge, Xavier Poiré, Guido Kobbe

Collection and assembly of data: Simona Iacobelli, Ruzena Uddin, Marleen van Os

Data analysis and interpretation: Nicolaus Kröger, Simona Iacobelli, Ronald Brand

Manuscript writing: All authors

Final approval of manuscript: All authors

Accountable for all aspects of the work: All authors

\section{REFERENCES}

1. Malcovati L, Hellström-Lindberg $E$, Bowen D, et al: Diagnosis and treatment of primary myelodysplastic syndromes in adults: Recommendations from the European LeukemiaNet. Blood 122: 2943-2964, 2013

2. Fenaux P, Mufti GJ, Hellstrom-Lindberg $E$, et al: Efficacy of azacitidine compared with that of conventional care regimens in the treatment of higher-risk myelodysplastic syndromes: A randomised, openlabel, phase III study. Lancet Oncol 10:223-232, 2009

3. Kröger N: Allogeneic stem cell transplantation for elderly patients with myelodysplastic syndrome. Blood 119:5632-5639, 2012

4. Deeg HJ, Shulman HM, Anderson JE, et al: Allogeneic and syngeneic marrow transplantation for myelodysplastic syndrome in patients 55 to 66 years of age. Blood 95:1188-1194, 2000

5. Lim Z, Brand R, Martino R, et al: Allogeneic hematopoietic stem-cell transplantation for patients 50 years or older with myelodysplastic syndromes or secondary acute myeloid leukemia. J Clin Oncol 28:405-411, 2010

6. McClune $B L$, Weisdorf DJ, Pedersen TL, et al: Effect of age on outcome of reduced-intensity hematopoietic cell transplantation for older patients with acute myeloid leukemia in first complete remission or with myelodysplastic syndrome. J Clin Oncol 28:1878-1887, 2010

7. Passweg JR, Baldomero $H$, Bader $P$, et al: Hematopoietic stem cell transplantation in Europe 2014: More than 40,000 transplabnts annually. Bone Marrow Transplant 51:786-792, 2016

8. Martino R, lacobelli $S$, Brand $R$, et al: Retrospective comparison of reduced-intensity conditioning and conventional high-dose conditioning for allogeneic hematopoietic stem cell transplantation using HLA-identical sibling donors in myelodysplastic syndromes. Blood 108:836-846, 2006

9. Martino $R$, de Wreede $L$, Fiocco $M$, et al: Comparison of conditioning regimens of various intensities for allogeneic hematopoietic SCT using HLA-identical sibling donors in AML and MDS with $<10 \%$ BM blasts: A report from EBMT. Bone Marrow Transplant 48:761-770, 2013

10. Luger SM, Ringdén O, Zhang MJ, et al: Similar outcomes using myeloablative vs reducedintensity allogeneic transplant preparative regimens for AML or MDS. Bone Marrow Transplant 47: 203-211, 2012

11. Shimoni A, Hardan I, Shem-Tov N, et al: Allogeneic hematopoietic stem-cell transplantation in AML and MDS using myeloablative versus reducedintensity conditioning: The role of dose intensity. Leukemia 20:322-328, 2006
12. Glucksberg $H$, Storb $R$, Fefer $A$, et al: Clinical manifestations of graft-versus-host disease in human recipients of marrow from HL-A-matched sibling donors. Transplantation 18:295-304, 1974

13. Shulman HM, Sullivan $K M$, Weiden $P L$, et al: Chronic graft-versus-host syndrome in man. A longterm clinicopathologic study of 20 Seattle patients. Am J Med 69:204-217, 1980

14. Bornhäuser $M$, Kienast J, Trenschel $R$, et al: Reduced-intensity conditioning versus standard conditioning before allogeneic haemopoietic cell transplantation in patients with acute myeloid leukaemia in first complete remission: A prospective, open-label randomised phase 3 trial. Lancet Oncol 13:1035-1044, 2012

15. Rambaldi A, Grassi A, Masciulli A, et al: Busulfan plus cyclophosphamide versus busulfan plus fludarabine as a preparative regimen for allogeneic haemopoietic stem-cell transplantation in patients with acute myeloid leukaemia: An open-label, multicentre, randomised, phase 3 trial. Lancet Oncol 16: 1525-1536, 2015

16. Scott $B L$, Pasquini $M C$, Logen $B$, et al: Results of a phase III randomized, multi-center study of allogeneic stem cell transplantation after high versus reduced intensity conditioning in patients with myelodysplastic syndrome (MDS) or acute myeloid leukemia (AML): Blood and Marrow Transplant Clinical Trials Network (BMT CTN) 0901. Blood 126, 2015 (abstr LBA-8) 


\section{Affiliations}

Nicolaus Kröger, University Medical Center Hamburg-Eppendorf, Hamburg; Georg-Nikolaus Franke, University Hospital Leipzig, Leipzig; Uwe Platzbecker, University Hospital Dresden, Dresden; Kai Hübel and Christof Scheid, University of Cologne, Cologne; Thomas Weber, University Hospital Halle (Saale), Martin-Luther-University Halle-Wittenberg, Halle; Matthias Stelljes, University of Münster, Münster; Peter Dreger, University of Heidelberg, Heidelberg; Andreas Günther, University Hospital Schleswig Holstein Campus Kiel, Kiel; Wolfgang Bethge, University Hospital Tübingen, Tübingen; Guido Kobbe, Heinrich Heine University, Düsseldorf, Germany; Simona Iacobelli, Università Tor Vergata, Rome; Giorgio Lambertenghi Deliliers and Francesco Onida, Fondazione IRCC Ca' Granda Ospedale Maggiore Policlinico, University of Milano, Milan; Massimo Pini, Azienda Ospedaliera SS. Antonio e Biagio e Cesare Arrigo, Alessandria; Stefano Guidi, Azienda Ospedaliera Universitaria Careggi, Florence, Italy; Ruzena Uddin, Guy's Hospital, London, United Kingdom; Marie Robin, Hôpital Saint Louis, Assistance Publique Hôpitaux Paris, France; Boris Afanasyev, SPB Pavlov Medical University, St Petersburg, Russia; Dominik Heim, University Hospital Basel, Basel Switzerland; Liisa Volin, Helsinki University Hospital, Helsiniki, Finland; Xavier Poiré, Cliniques Universitaires St-Luc, Brussels, Belgium; Marleen van Os, European Group of Blood and Marrow Transplantation Clinical Trials Office; Ronald Brand, Leiden University Medical Center, Leiden; and Theo de Witte, Radboud University Medical Center, Nijmegen, the Netherlands.

Supported in part by a grant from Pierre Fabre.

\section{Support}

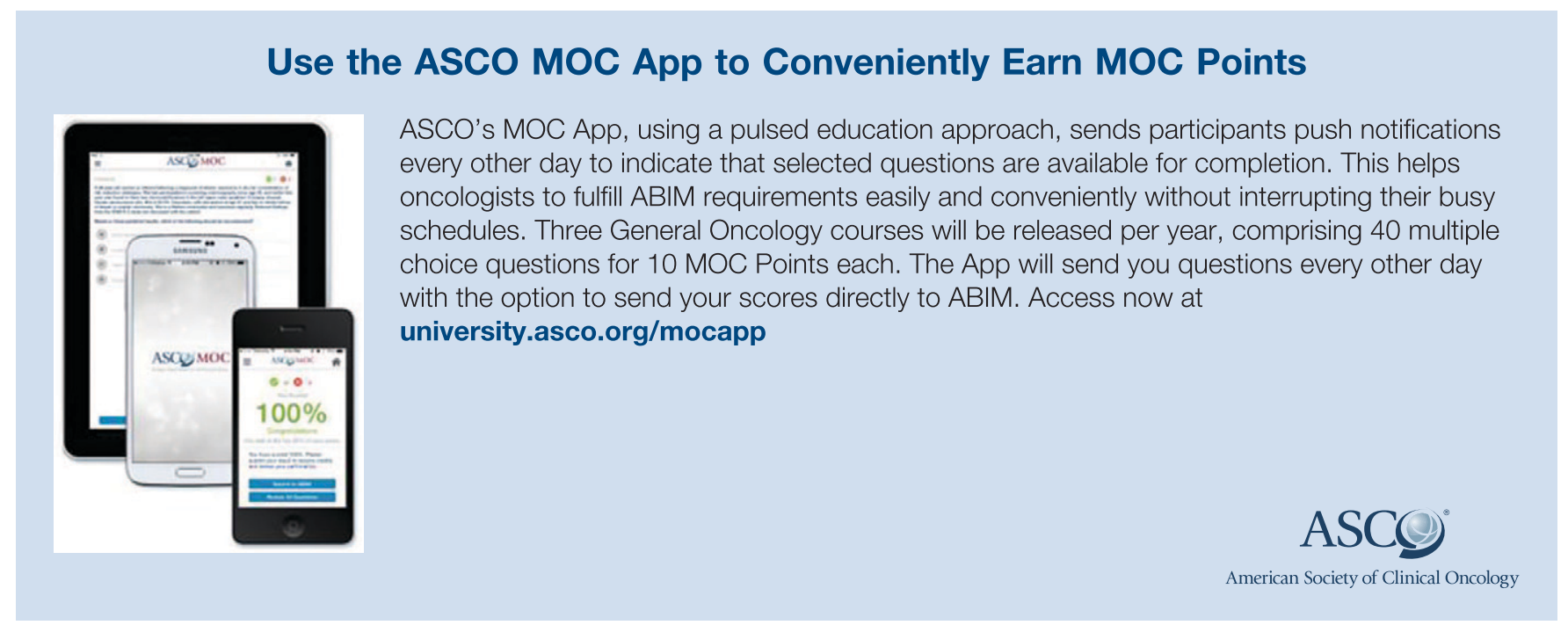




\section{AUTHORS' DISCLOSURES OF POTENTIAL CONFLICTS OF INTEREST}

Dose-Reduced Versus Standard Conditioning Followed by Allogeneic Stem-Cell Transplantation for Patients With Myelodysplastic Syndrome: A Prospective Randomized Phase III Study of the EBMT (RICMAC Trial)

The following represents disclosure information provided by authors of this manuscript. All relationships are considered compensated. Relationships are self-held unless noted. I = Immediate Family Member, Inst = My Institution. Relationships may not relate to the subject matter of this manuscript. For more information about ASCO's conflict of interest policy, please refer to www.asco.org/rwc or ascopubs.org/jco/site/ifc.

\section{Nicolaus Kröger}

Honoraria: Novartis, Neovii, Gilead Sciences

Consulting or Advisory Role: Medac, Novartis, Neovii

Research Funding: Neovii (Inst), Riemser (Inst), Celgene (Inst)

\section{Simona Iacobelli}

No relationship to disclose

\section{Georg-Nikolaus Franke}

No relationship to disclose

Uwe Platzbecker

No relationship to disclose

\section{Ruzena Uddin}

No relationship to disclose

\section{Kai Hübel}

No relationship to disclose

\section{Christof Scheid}

Honoraria: Novartis, Bristol-Myers Squibb, Amgen, Celgene, Janssen Oncology

Thomas Weber

Consulting or Advisory Role: MSD

Travel, Accommodations, Expenses: Roche, AbbVie, Takeda

Pharmaceuticals, Celgene, Gilead Sciences

\section{Marie Robin}

No relationship to disclose

\section{Matthias Stelljes}

No relationship to disclose

Boris Afanasyev

No relationship to disclose

\section{Dominik Heim}

No relationship to disclose

Giorgio Lambertenghi Deliliers

No relationship to disclose

\section{Francesco Onida}

No relationship to disclose

\section{Peter Dreger}

No relationship to disclose

Massimo Pini

No relationship to disclose

Stefano Guidi

No relationship to disclose

Liisa Volin

No relationship to disclose

\section{Andreas Güenther}

Honoraria: Janssen Pharmaceuticals, Celgene

Consulting or Advisory Role: Takeda Pharmaceuticals, Novartis

Travel, Accommodations, Expenses: Amgen, Novartis

Wolfgang Bethge

Consulting or Advisory Role: Miltenyi Biotec

Research Funding: Neovii Biotech (Inst), Pfizer (Inst), Medac (Inst)

Travel, Accommodations, Expenses: Medac

\section{Xavier Poiré}

No relationship to disclose

\section{Guido Kobbe}

No relationship to disclose

Marleen van Os

No relationship to disclose

\section{Ronald Brand}

No relationship to disclose

Theo de Witte

Honoraria: Novartis, Celgene, Incyte

Research Funding: Novartis (Inst) 


\section{Appendix}

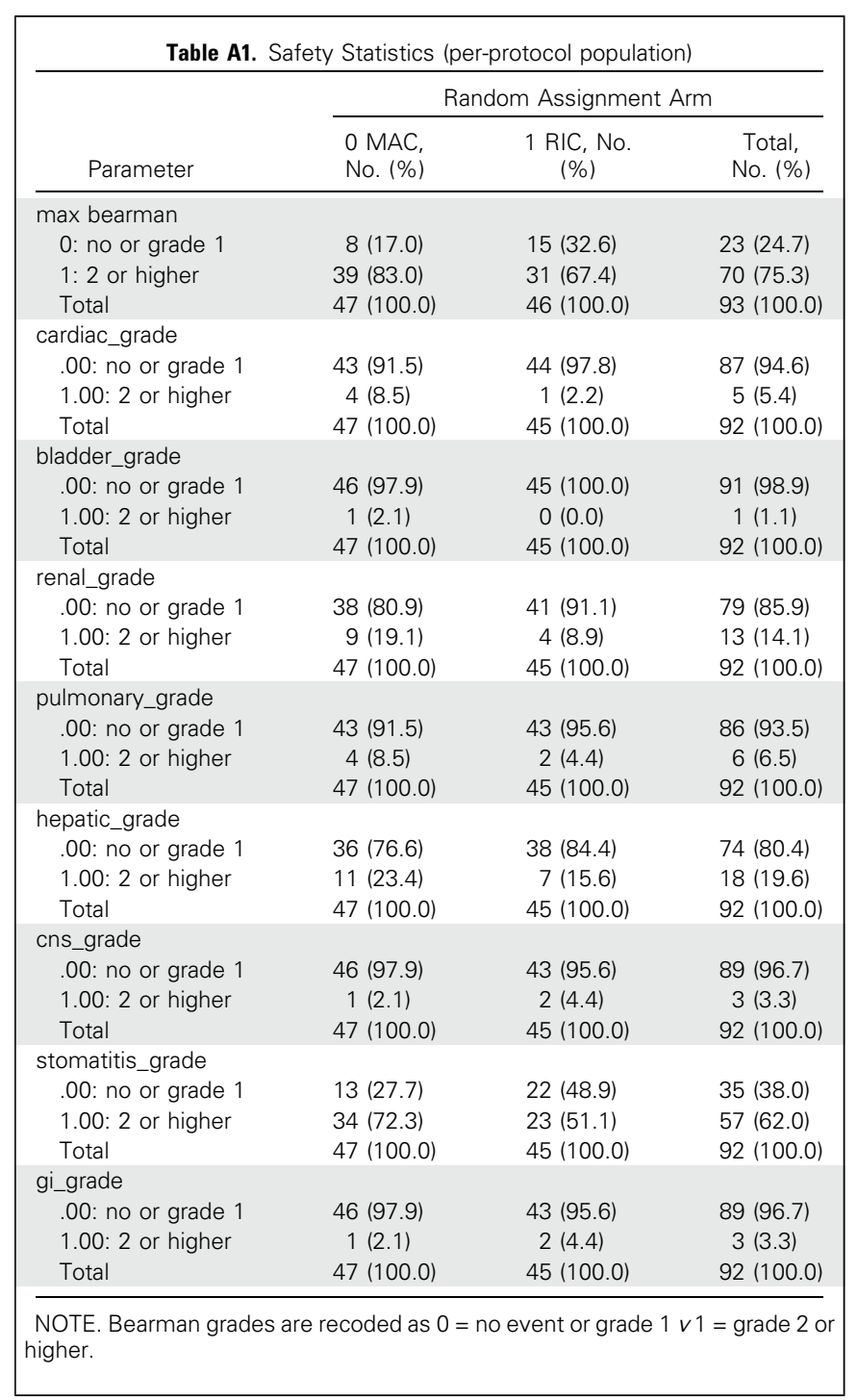

\begin{tabular}{|c|c|c|}
\hline Parameter & $\chi^{2}$ Test & Fisher's Exact Test \\
\hline max Bearman & 0.082 & 0.097 \\
\hline cardiac_grade & $0.184^{*}$ & 0.362 \\
\hline bladder_grade & $0.325^{*} \dagger$ & 1.000 \\
\hline renal_grade & $0.158^{*}$ & 0.232 \\
\hline pulmonary_grade & $0.430^{*}$ & 0.677 \\
\hline hepatic_grade & 0.343 & 0.434 \\
\hline cns_grade & $0.532^{*}$ & 0.613 \\
\hline stomatitis_grade & 0.036 & 0.053 \\
\hline gi_grade & $0.532^{*}$ & 0.613 \\
\hline \multicolumn{3}{|c|}{$\begin{array}{l}\text { NOTE. Because of the small numbers, the } \chi^{2} \text { test can be invalid, in which case } \\
\text { Fisher's exact test is more appropriate. } \\
\text { * More than } 20 \% \text { of cells in this table have expected cell counts }<5 . \chi^{2} \text { results } \\
\text { may be invalid. } \\
\text { †The minimum expected cell count in this table is }<1 . \chi^{2} \text { results may be invalid. }\end{array}$} \\
\hline
\end{tabular}

